Pediat. Res. 6: 487-494 (1972)

Erythroblastosis fetalis erythrocytes fatty acids neonates phospholipids rhesus factor

\title{
Fatty Acid Composition of Phospholipids in Erythrocytes of Adults, Normal Newborn Infants, and Neonates with Rh Erythroblastosis
}

\author{
G. Gercken ${ }^{[63]}$, T. Tiling, U. Brockmann, and W. Schröter \\ Departments of Biochemistry and Pediatrics, University of Hamburg, Hamburg, West Germany
}

Extract

The fatty acid patterns of the total phospholipids (PL) and the individual PL, namely phosphatidyl choline (PC), phosphatidyl ethanolamine (PE), phosphatidyl serine (PS), and sphingomyelin (SP), in erythrocytes from five adults, five healthy newborn infants, and four neonates with $\mathrm{Rh}$ erythroblastosis were analyzed by gas-liquid chromatography (GLC) after the PL had been separated by thin layer chromatography (TLC). The content of linoleic acid in the total PL in erythrocytes of newborn infants was significantly smaller than in erythrocytes of adults $(3.8 \%$ versus $11.9 \%$ of total fatty acid content). Furthermore, the contents of $20: 1_{n-9}, 20: 5_{n-3}$, and $22: 5_{n-3}$ were also smaller. The concentrations of the saturated fatty acids $16: 0$ and $20: 0$ and of the unsaturated fatty acids $20: 3_{n-9}, 22: 3_{n-9}, 20: 3_{n-6}, 20: 4_{n-6}, 22: 5_{n-6}$, and $22: 6_{n-3}$ were significantly larger. Within the oleate, linoleate, and linolenate family, there was a shift toward more highly unsaturated fatty acids. Corresponding changes were found in the fatty acid patterns of the individual PL. The fatty acid pattern in erythrocytes from newborn infants resembled that induced by a deficiency of essential fatty acids. The fatty acid pattern of the total PL in erythrocytes from neonates with Rh erythroblastosis corresponded to that of normal newborn infants, whereas there were only slight differences in the fatty acid compositions of the individual PL. Thus, a change in the lipid and fatty acid compositions cannot account for the hemolysis caused by antibodies.

\section{Speculation}

The pattern of fatty acids of PL in erythrocytes from newborn infants differs from that of adults. The difference is obviously the result of a deficiency of essential fatty acids in the fetus. This lack could be induced by a permeability barrier in the placenta or by insufficient binding of lipids onto the plasma proteins of the fetus. Insufficient uptake of fatty acids by the fetus is recognizable by a decreased content of essential fatty acids, since the other fatty acids can be synthesized de novo by the fetus.

\section{Introduction}

Erythrocytes of newborn infants and adults differ in their PL composition and fatty acid patterns $[6,12,23$,
30]. Deviations in the composition of membrane PL may reflect the lowered content and altered distribution of lipids and lipoproteins in fetal plasma $[6,50$, 
51]. The results obtained from lipid analysis of plasma and erythrocytes in patients with abetalipoproteinemia (acanthocytosis) also suggest an interdependence between plasma and membrane lipids [31, 45]. The fatty acid content of neutral and phospholipids in the plasma and the erythrocyte membrane reflects the characteristics of fetal fatty acid metabolism: viz., the possibility of de novo synthesis of saturated fatty acids and fatty acids of the oleic acid family, and the necessity to obtain essential fatty acids through the placenta [34]. Unsaturated fatty acids can then be transformed by chain elongation and desaturation by fetal metabolism as is demonstrated by increased concentrations of rare unsaturated fatty acids (e.g., 20:3 $3_{\mathrm{n}-9}$ ) and long chain polyunsaturated fatty acids. (Fatty acids are designated by number of carbon atoms:number of double bonds. The position of the double bonds is stated as $n-x$ where $x$ indicates the carbon number of the first unsaturated bond counting from the methyl end of the chain.)

Are the deviating PL and fatty acid compositions of erythrocytes of newborn infants of significance in accounting for the known differences of these cells: e.g., shortened life span, great sensitivity toward oxidative drugs, changed permeability for cations and nonelectrolytes, and decreased mechanical resistance? The lesser permeability to glycerol of the erythrocytes of newborn infants, described by Moore [28], can be explained by the greater amount of saturated fatty acids which stabilize the membrane, and by the relation between membrane stabilization and decreased permeability [15].

In the present investigation we analyzed the largest possible number of fatty acids of total PL, after TLC isolation from neutral and glycosphingolipids, and of individual PL, after TLC fractionation. The fatty acid patterns were compared with those of erythrocytes from adults and from neonates with $\mathrm{Rh}$ erythroblastosis. We discuss the regulation of fetal fatty acid metabolism in reference to the alterations in essential fatty acid deficiency. Regulation of the desaturation system in the fetus [3, 21] explains, for example, the increased amount of arachidonic acid normally found. Thus the question raised by Robertson and Sprecher [34] as to whether this fatty acid is taken up preferably through the placenta by the fetus, is not germane.

\section{Materials and Methods}

Venous blood $(10 \mathrm{ml})$ was obtained from each of five adults who were 22-35 years old and apparently healthy. Aliquots of cord blood were obtained from five normal newborn infants and from four neonates with $\mathrm{Rh}$ erythroblastosis who had a 3 to 4 times positive Coombs' test. Anamnesis of the adults and mothers revealed that no subject was on a special diet or had a metabolic disease. The blood was anticoagulated with heparin [52] and stored at $4^{\circ}$ no longer than $3 \mathrm{hr}$ before processing. Erythrocytes were isolated by centrifugation $(1000 \times g, 5 \mathrm{~min})$ and were then washed 3 times with an equal volume of isotonic $\mathrm{NaCl}$ solution; the buffy coat and the top $15 \%$ of the erythrocyte mass were discarded [23]. In the final suspension there were $4.2 \times 10^{6}$ to $9.7 \times 10^{6}$ erythrocytes $/ \mathrm{mm}^{3}, 0-50$ leukocytes $/ \mathrm{mm}^{3}$, and $0.6-1.5 \%$ reticulocytes.

\section{Extraction of Lipids}

Extraction was carried out by a modified procedure of Ways and Hanahan [4, 44]. Three milliliters of packed erythrocytes were added to $15 \mathrm{ml}$ cold methanol [53] and homogenized by an Ultra-Turrax [54] at 5 -min intervals. The homogenate was kept in an ice bath under nitrogen. After $30 \mathrm{~min}, 15 \mathrm{ml}$ chloroform were added and the mixture was allowed to stand for $15 \mathrm{~min}$. The solutions were then filtered, using a rapid filter previously washed with methanol. The residue was rinsed with $15 \mathrm{ml}$ chloroform and $15 \mathrm{ml}$ methanol. The filtrate was evaporated to near dryness in vacuo at $37^{\circ}$ and the residue was solubilized successively with 30 $\mathrm{ml}$ chloroform, $15 \mathrm{ml}$ methanol, and $9 \mathrm{ml} 0.1 \mathrm{M} \mathrm{KCl}$ solution. The solutions were pooled in a separatory funnel. The mixture was shaken and left to stand for 4 hr at $4^{\circ}$ for phase separation. After being warmed to room temperature, the lower phase was collected in a $500-\mathrm{ml}$ flask and the upper phase was reextracted with $10 \mathrm{ml}$ chloroform. The pooled lower phases were evaporated to dryness in vacuo at $37^{\circ}$ in a rotary vacuum evaporator. The lipid residue was dissolved in $2 \mathrm{ml}$ chloroform. To avoid autoxidation, $50 \mathrm{mg}$ 4-methyl2,6-di-tert-butylphenol (BHT) [55] were added to 100 $\mathrm{ml}$ chloroform or methanol, which were used for extraction as well as for TLC.

\section{Separation of Phospholipids and Fatty Acid Methyl Es- ters}

PL in the lipid extract were separated from glycolipids and neutral lipids by preparative TLC according to a modified method of Skipski et al. [37] using silica gel HR-magnesium silicate $4: 1$ (w/w), $0.5 \mathrm{~mm}$ thick, and a chloroform-pyridine-water 50:75:5 (v/v) solvent system. Plates were activated overnight at $150^{\circ}$ and 
were used immediately after they had cooled to room temperature. The total lipid extract of the sample (10 $\mathrm{ml}$ blood) was delivered by pipette onto TLC plates as a 16-cm long band. During separation, PL remained near the origin and appeared as two fractions. Glycolipids fractionated into globoside I [49], triglycosyl and diglycosyl ceramide, while cholesterol and free fatty acids moved near the front. After development, the plates were dried in a vacuum oven at $35^{\circ}$ for $20 \mathrm{~min}$ to remove the solvents.

The PL fractions were made visible by spraying with molybdenum reagent [8] on two narrow guide stripes. For determination of total fatty acid composition, one-third of the length of the PL bands was transferred into glass tubes with screw caps. The remaining two-thirds was scraped directly onto a sintered filter [56] and the PL were then extracted successively with $50 \mathrm{ml}$ each of chloroform-methanol $\mathrm{l}: \mathrm{l}$ $(\mathrm{v} / \mathrm{v})$, methanol-chloroform $6: 1(\mathrm{v} / \mathrm{v})$, methanol-water 8:1 (v/v) and ethanol-methanol-water 5:2:2 (v/v) [7, 14]. The extract was evaporated to dryness in a rotary vacuum evaporator, and the $\mathrm{PL}$ were dissolved in $2 \mathrm{ml}$ chloroform. PL were then separated into the PL classes PC, PE, PS, and SP by TLC on silica gel HR, $0.5 \mathrm{~mm}$ thick, with a chloroform-methanol-acetic acid-water $60: 30: 8: 4(\mathrm{v} / \mathrm{v})$ solvent system [36]. Plates were activated at $120^{\circ}$ for $2 \mathrm{hr}$. The bands were made visible by spraying with molybdenum reagent on two narrow guide stripes and then they were scraped into glass tubes with screw caps.

Recovery of eluted PL was demonstrated by the method of Bartlett [2], modified according to Brockmann and Gercken [4]; $91.3 \%$ of the total PL were recovered after TLC for isolation of total $\mathrm{PL}$, and 93.8\% after TLC for separation of individual PL. For transesterification, $2 \mathrm{ml}$ methanolic boron trifluoride (14\% by weight) $[26,46]$ were added. The tubes were flushed with nitrogen, closed, and heated in boiling water: $90 \mathrm{~min}$ for total $\mathrm{PL}$ and SP, $30 \mathrm{~min}$ for PC, and 10 min for PE and PS [29]. The methyl esters and dimethyl acetals were extracted twice into hexane by addition of $8 \mathrm{ml}$ hexane followed by $2 \mathrm{ml} 5 \mathrm{~N} \mathrm{NaOH}$ and $2 \mathrm{ml}$ water at $0^{\circ}$.

Methyl esters were separated from dimethyl acetals and other products of methylation by TLC on silica gel HR, $0.5 \mathrm{~mm}$ thick, with benzene as the solvent [29]. After development and marginal detection by iodine vapor, the unstained fatty acid methyl esters (FAME) were scraped off and extracted from the silica gel successively by $40 \mathrm{ml}$ hexane, $50 \mathrm{ml}$ diethyl ether, and $10 \mathrm{ml}$ hexane. The combined eluates were concen- trated to about $200 \mu$ liters and used for analysis by GLC.

The FAME of total PL were further fractionated according to their degree of unsaturation by TLC on silica gel G-silver nitrate $5: 1(\mathrm{w} / \mathrm{w}), 0.5 \mathrm{~mm}$ thick, with a hexane-diethyl ether 20:80 (v/v) solvent system [14]. This additional fractionation aided the identification and quantification of FAME which appeared in overlapping peaks on GLC. The fractions were made visible in ultraviolet light by spraying with rhodamine $\mathrm{B}$ $[16,40]$.

\section{Gas-Liquid Chromatography}

The gas-liquid chromatograph [57] was equipped with paired 6-ft columns of EGSS-X $10 \%$ on GasChrom P, 100-120 mesh [58], and dual flame ionization detectors (FID). The helium flow rate was $43 \mathrm{ml} /$ min. The column temperature was maintained at $170-180^{\circ}$, that of the flash heater at $250^{\circ}$, and that of FID at $245^{\circ}$. Peaks were identified by the carbon numbers (ECL) $[27,48]$ and by calculation of separation factors [1, 18, 24], Types I and IV according to Haken [19]. Methyl esters of the following fatty acids were used as reference standards: $8: 0-22: 0$ and $24: 0$; $16: 1_{n-7}, 18: 1-24: 1_{n-9}$ (even carbon); $18: 2_{n-6}, 18: 3_{n-3}$, $20: 4_{n-6}, 20: 5_{n-3}$, and $22: 6_{n-3}$ [59]. Identification of FAME was confirmed by GLC of total PL FAME on a second polar column DEGS, 6\%, and on an apolar column SE 30, both on Diaport S, 80-100 mesh [60].

Peak areas were calculated by multiplication of the absolute retention volumes by the peak height; values are given as area percentages. The values were not converted into weight percentage, because the detector response factors showed no regularity corresponding to chain length, number and position of clouble bonds. Deviations of peak area percentage from weight percentage for FAME standards were $\pm 5 \%$ when 20:0 was taken as $100 \%$ for chain lengths of 18-22 carbon atoms and $-11 \%$ for palmitic acid. Myristic acid was not quantified because BHT emerged with a retention volume similar to that of myristic acid methyl ester. The peak area of palmitoleic acid methyl ester was enlarged by a methylation product of BHT.

\section{Results}

\section{Fatty Acid Composition of Total Phospholipids of Erythrocytes (Table I)}

The pattern of fatty acids in erythrocytes of newborn infants differed significantly from that in erythro- 
Table I. Fatty acid composition of total phospholipids in erythrocytes ${ }^{1}$

\begin{tabular}{|c|c|c|c|}
\hline Fatty acid & Adults & Newborn infants & $\begin{array}{c}\text { Neonates with } \\
\mathrm{Rh} \text { erythroblastosis }\end{array}$ \\
\hline $15: 0$ & $0.26 \pm 0.07$ & $0.09 \pm 0.02$ & $0.09 \pm 0.02$ \\
\hline $14: 2 n-6$ & $0.06 \pm 0.06$ & Trace & Trace \\
\hline $16: 0$ & $17.4 \pm 1.5$ & $20.8 \pm 1.9^{2}$ & $20.2 \pm 3.6$ \\
\hline $16: 1_{n-7}$ & $0.72 \pm 0.37$ & $1.1 \pm 0.1$ & $1.1 \pm 0.2$ \\
\hline $17: 0$ & $0.33 \pm 0.10$ & $0.37 \pm 0.14$ & $0.35 \pm 0.09$ \\
\hline $\left.\begin{array}{l}16: 2_{n-9^{3}} \\
16: 2_{n-6}\end{array}\right\}$ & $0.20 \pm 0.28$ & $0.07 \pm 0.04$ & Trace \\
\hline $18: 0$ & $13.4 \pm 0.9$ & $14.4 \pm 1.3$ & $13.8 \pm 2.9$ \\
\hline $18: 1_{n-9}$ & $13.1 \pm 0.3$ & $11.2 \pm 2.0$ & $11.5 \pm 1.2$ \\
\hline 19:0 & $0.15 \pm 0.04$ & Trace & Trace \\
\hline $18: 2_{n-6}$ & $11.9 \pm 1.3$ & $3.8 \pm 0.4^{4}$ & $4.8 \pm 2.0$ \\
\hline $20: 0$ & $0.26 \pm 0.08$ & $0.45 \pm 0.15^{2}$ & $0.26 \pm 0.21$ \\
\hline $\left.\begin{array}{l}18: 3_{n-3^{3}} \\
20: 1_{n-9}\end{array}\right\}$ & $0.56 \pm 0.10$ & $0.29 \pm 0.06^{4}$ & $0.28 \pm 0.05$ \\
\hline $20: 2_{n-9}$ & $0.17 \pm 0.03$ & $0.17 \pm 0.09$ & $0.15 \pm 0.05$ \\
\hline $20: 2_{n-6}$ & $0.26 \pm 0.09$ & $0.16 \pm 0.04$ & $0.22 \pm 0.04$ \\
\hline $20: 3_{n-9}$ & Trace & $0.85 \pm 0.50^{4}$ & $0.51 \pm 0.10$ \\
\hline $\left.\begin{array}{l}20: 3_{n-6} \\
22: 0\end{array}\right\}$ & $2.7 \pm 0.2$ & $3.6 \pm 0.3^{4}$ & $2.9 \pm 0.2$ \\
\hline $20: 4_{n-6}$ & $15.5 \pm 2.6$ & $19.2 \pm 2.1^{2}$ & $19.0 \pm 4.8$ \\
\hline $22: 1_{n-9}$ & $0.18 \pm 0.09$ & $0.21 \pm 0.03$ & $0.10 \pm 0.18$ \\
\hline $\left.\begin{array}{l}20: 4_{n-3^{3}} \\
23: 0\end{array}\right\}$ & $1.7 \pm 1.0$ & $0.69 \pm 0.18$ & $0.50 \pm 0.42$ \\
\hline $22: 2_{n-9}$ & $0.16 \pm 0.13$ & Trace & \\
\hline $\left.\begin{array}{l}20: 5_{n-3} \\
22: 2_{n-6^{3}}\end{array}\right\}$ & $0.94 \pm 0.18$ & $0.29 \pm 0.10^{4}$ & $0.35 \pm 0.27$ \\
\hline $22: 3_{n-9}$ & $0.10 \pm 0.04$ & $0.51 \pm 0.17^{4}$ & $0.46 \pm 0.13$ \\
\hline $24: 0$ & $2.9 \pm 0.7$ & $3.1 \pm 1.3$ & $2.2 \pm 2.3$ \\
\hline $22: 4_{n-9}$ & & & $0.07 \pm 0.08$ \\
\hline $\left.\begin{array}{l}22: 4_{n-6^{5}} \\
24: 1_{n-9}\end{array}\right\}$ & $6.5 \pm 0.6$ & $6.4 \pm 0.8$ & $7.7 \pm 1.5$ \\
\hline $22: 5_{n-6}$ & $0.37 \pm 0.02$ & $1.5 \pm 0.4^{4}$ & $1.8 \pm 1.2$ \\
\hline $22: 5_{n-3}$ & $3.4 \pm 0.8$ & $1.1 \pm 0.3^{4}$ & $1.5 \pm 0.8$ \\
\hline $\left.\begin{array}{l}22: 6_{n-3} \\
26: 0^{3}\end{array}\right\}$ & $6.8 \pm 1.0$ & $9.4 \pm 1.8^{2}$ & $9.4 \pm 3.1$ \\
\hline $24: 4_{n-6}$ & $0.19 \pm 0.36$ & $0.24 \pm 0.10$ & $0.26 \pm 0.06$ \\
\hline $26: 1_{n-9}$ & $0.09 \pm 0.11$ & Trace & $0.26 \pm 0.31$ \\
\hline
\end{tabular}

1 Values, in percentage of peak areas, are given as means $\pm \mathrm{SD}$. Statistical comparison is between neonates and adults by $t$ test. ${ }^{2} P<0.05$.

${ }^{3}$ Approximately $5 \%$ of this peak area.

${ }^{4} P<0.01$.

${ }^{5}$ Approximately $40 \%$ of this peak area.

cytes of adults. The content of linoleic acid was much lower in erythrocytes of newborn infants; in addition, the contents of 20:1 from the oleic acid family and of $20: 5$ and $22: 5$ from the linolenic acid family were also lower. Contents of the saturated fatty acids $16: 0$ and 20:0 and of the unsaturated fatty acids $20: 3_{\mathrm{n}-9}$, $22: 3_{n-9}, 20: 3_{n-6}, 20: 4_{n-6}, 22: 5_{n-6}$, and $22: 6_{n-3}$ were greater in erythrocytes of newborn infants. The contents of fatty acids with two and five double bonds were significantly smaller and those with three, four, and six double bonds were significantly greater. The fatty acid patterns in erythrocytes from newborn infants with $\mathrm{Rh}$ erythroblastosis and from normal newborn infants were similar.

\section{Fatty Acid Composition of Individual Phospholipids of Erythrocytes}

Tables II and III show the patterns of fatty acids in the four major PL (PC, PE, PS, and SP) of erythrocytes from adults and newborn infants. Most of the differences between newborn and adult erythrocytes were in the fatty acid composition of PE. The proportion of $16: 1_{n-7}$ was greater in erythrocytes of newborn infants than in those of adults. The content of $18: 2_{n-6}$ was significantly smaller, while the amounts of unsaturated fatty acids of the oleic acid family, 20:3 and 22:3, were compensatorily greater. The amount of $22: 5_{n-6}$ was significantly greater and that of $22: 5_{n-3}$ was significantly smaller. The increase of $20: 4_{n-6}$ in the fatty acid composition of total PL was due to its increased content in PG. The content of 18:0 was markedly greater in PS and SP. No differences were found in the fatty acid composition of total PL in erythrocytes from newborn infants and neonates with $\mathrm{Rh}$ erythroblastosis, and there were only a few significant alterations in the fatty acid composition of the individual PL.

\section{Discussion}

The fatty acid pattern of the total PL of erythrocytes from adults which we found was in good agreement with the findings of Dodge and Phillips [9]; they determined a similarly differentiated fatty acid pattern. This contrasts with the fewer fatty acids reported by other investigators $[5,10-12,20,25,30,39,44,47]$. Furthermore, there was good agreement in the fatty acid patterns of $\mathrm{PE}$ and $\mathrm{PC}$, but great differences in that of PS: we found higher values for $16: 0,18: 1_{n-9}$, $22: 2_{\mathrm{n}-9}, 22: 2_{\mathrm{n}-6}+20: 5_{\mathrm{n}-3}$, and $22: 3_{\mathrm{n}-9}$, lower values for $18: 0$ and $22: 4_{n-6}+24: 1_{n-9}$. These differences were probably due to incomplete elution of PS from the silica gel by Dodge and Phillips [9]; this might change the composition of the molecular species. For example, we recovered only $50 \%$ of the PS in the extract by eluting with chloroform and methanol, but $89 \%$ by the described elution with solvents of increasing polarity. In the fatty acid pattern of SP, we found smaller contents of 24:0 and 24:1 $1_{n-9}$ than did Dodge and Phillips [9]; their SP fraction may contain glycolipids, in which these fatty acids are very common. In the TLC separa- 
Table II. Fatty acid composition of the four major phospholipids in erythrocytes from five normal adults ${ }^{1}$

\begin{tabular}{|c|c|c|c|c|}
\hline Fatty acid & $\mathrm{PE}^{2}$ & $\mathrm{PS}^{3}$ & $\mathrm{PC}^{4}$ & $\mathrm{SP}^{5}$ \\
\hline $15: 0$ & $0.13 \pm 0.04$ & $0.11 \pm 0.06$ & $0.28 \pm 0.16$ & $0.22 \pm 0.23$ \\
\hline $14: 2_{n-6}$ & $0.08 \pm 0.13$ & $0.07 \pm 0.09$ & $0.07 \pm 0.03$ & Trace \\
\hline $16: 0$ & $12.2 \pm 2.8$ & $8.4 \pm 5.1$ & $31.2 \pm 7.2$ & $26.4 \pm 11.0$ \\
\hline $16: 1_{n-7}$ & $0.84 \pm 0.68$ & $1.7 \pm 2.2$ & $1.7 \pm 0.7$ & $3.0 \pm 1.7$ \\
\hline $17: 0$ & $0.28 \pm 0.11$ & $0.32 \pm 0.38$ & $0.51 \pm 0.18$ & $0.59 \pm 0.30$ \\
\hline $\left.\begin{array}{l}16: 2_{n-9} \\
16: 2_{n-6}\end{array}\right\}$ & $0.32 \pm 0.38$ & $0.37 \pm 0.48$ & $0.18 \pm 0.23$ & $0.47 \pm 0.41$ \\
\hline $18: 0$ & $10.0 \pm 4.3$ & $28.9 \pm 3.8$ & $12.7 \pm 2.7$ & $7.1 \pm 2.9$ \\
\hline $18: l_{n-9}$ & $15.7 \pm 2.7$ & $11.6 \pm 5.8$ & $15.4 \pm 1.5$ & $1.6 \pm 0.8$ \\
\hline $19: 0$ & $0.16 \pm 0.09$ & $0.45 \pm 0.39$ & $0.36 \pm 0.24$ & $0.10 \pm 0.05$ \\
\hline $18: 2_{n-6}$ & $6.4 \pm 1.2$ & $3.8 \pm 1.9$ & $17.0 \pm 5.7$ & $0.85 \pm 0.82$ \\
\hline $20: 0$ & $0.08 \pm 0.03$ & $0.23 \pm 0.21$ & $0.10 \pm 0.04$ & $1.9 \pm 0.3$ \\
\hline $\left.\begin{array}{l}18: 3_{n-3} \\
20: 1_{n-9}\end{array}\right\}$ & $0.78 \pm 0.13$ & $0.58 \pm 0.28$ & $0.46 \pm 0.05$ & $0.34 \pm 0.21$ \\
\hline $20: 2_{n-9}$ & $0.18 \pm 0.05$ & $0.10 \pm 0.02$ & $0.19 \pm 0.08$ & $0.33 \pm 0.32$ \\
\hline $20: 2 n-6$ & $0.23 \pm 0.09$ & $0.24 \pm 0.11$ & $0.39 \pm 0.18$ & $0.11 \pm 0.28$ \\
\hline $20: 3_{n-9}$ & $0.05 \pm 0.03$ & $0.13 \pm 0.09$ & $0.20 \pm 0.24$ & $0.06 \pm 0.10$ \\
\hline $\left.\begin{array}{l}20: 3_{n-6} \\
22: 0\end{array}\right\}$ & $1.2 \pm 0.5$ & $1.4 \pm 0.9$ & $1.8 \pm 0.8$ & $8.8 \pm 1.5^{6}$ \\
\hline $20: 4_{n-6}$ & $25.6 \pm 8.1$ & $19.0 \pm 6.2$ & $5.6 \pm 2.5$ & $1.5 \pm 0.6$ \\
\hline $22: 1_{n-9}$ & $0.24 \pm 0.12$ & $0.21 \pm 0.13$ & $0.09 \pm 0.04$ & $0.37 \pm 0.34$ \\
\hline $\left.\begin{array}{l}20: 4_{n-3} \\
23: 0\end{array}\right\}$ & $1.7 \pm 0.9$ & $2.3 \pm 1.7$ & $1.6 \pm 1.0$ & $4.6 \pm 1.1$ \\
\hline $22: 2 n-9$ & $0.19 \pm 0.09$ & $0.32 \pm 0.28$ & $0.17 \pm 0.14$ & $0.33 \pm 0.31$ \\
\hline $\left.\begin{array}{l}20: 5_{n-3} \\
22: 2_{n-6}\end{array}\right\}$ & $1.7 \pm 0.3$ & $0.74 \pm 0.21$ & $0.70 \pm 0.55$ & $0.40 \pm 0.38$ \\
\hline $22: 3_{n-9}$ & $0.13 \pm 0.13$ & $0.13 \pm 0.11$ & $0.07 \pm 0.06$ & $0.32 \pm 0.11$ \\
\hline $24: 0$ & Trace & Trace & $0.09 \pm 0.28$ & $17.2 \pm 7.0$ \\
\hline $22: 4 n-9$ & $0.05 \pm 0.06$ & Trace & $0.14 \pm 0.36$ & Trace \\
\hline $\left.\begin{array}{l}22: 4_{n-6} \\
24: 1_{n-9}\end{array}\right\}$ & $5.4 \pm 1.6$ & $2.7 \pm 0.9$ & $1.8 \pm 1.1$ & $19.3 \pm 9.8^{7}$ \\
\hline $22: 5_{n-6}$ & $0.71 \pm 0.36$ & $0.69 \pm 0.37$ & $0.10 \pm 0.74$ & $1.1 \pm 0.53$ \\
\hline $22: 5_{n-3}$ & $5.7 \pm 1.8$ & $4.0 \pm 1.1$ & $0.83 \pm 0.57$ & $0.42 \pm 0.33$ \\
\hline $\left.\begin{array}{l}22: 6_{n-3} \\
26: 0\end{array}\right\}$ & $9.9 \pm 1.9$ & $10.3 \pm 4.8$ & $2.7 \pm 1.3$ & $0.98 \pm 0.13$ \\
\hline $24: 4_{n-6}$ & $0.12 \pm 0.02$ & Trace & & $1.3 \pm 1.7$ \\
\hline $26: 1_{n-9}$ & $0.08 \pm 0.12$ & Trace & & Trace \\
\hline
\end{tabular}

1 Values, in percentage of peak areas, are given as means \pm sD.

${ }^{2} \mathrm{PE}$ : phosphatidyl ethanolamine.

3 PS: phosphatidyl serine.

${ }^{4} \mathrm{PC}$ : phosphatidyl choline.

${ }^{5} \mathrm{SP}$ : sphingomyelin.

6 Appears to be largely 22:0.

${ }^{7}$ Appears to be largely $24: l_{n-9}$.

tion of PL on silica gel HR with chloroform-methanolacetic acid-water, part of the glycolipids overlaps the SP fraction. The preseparation with hexane-diethyl ether-acetic acid by Dodge and Phillips [9] separated only the neutral lipids while the glycolipids remained at the origin together with the PL.

The pattern of fatty acids in the total PL of erythrocytes from newborn infants has been determined so far by Crowley et al. [6], Farquhar and Ahrens [12], and
Neerhout [30]. These authors reported that the major components of the PL fatty acid pattern were present in relatively greater quantities because they identified fewer fatty acids than we did. Furthermore, they reported a smaller content of long chain polyunsaturated fatty acids and a greater amount of 24:0. We could confirm the larger proportions of 16:0, 20:3, $20: 4$, and 22:6 and the smaller proportion of $18: 2$ reported by Neerhout [30]. 
Table III. Fatty acid composition of the four major phospholipids in erythrocytes from five normal neonates ${ }^{1}$

\begin{tabular}{|c|c|c|c|c|}
\hline Fatty acid & $\mathrm{PE}^{2}$ & $\mathrm{PS}^{3}$ & $\mathrm{PC}^{4}$ & $\mathrm{SP}^{5}$ \\
\hline $15: 0$ & $0.19 \pm 0.18$ & Trace & $0.18 \pm 0.08$ & $0.07 \pm 0.02$ \\
\hline $14: 2_{n-6}$ & $0.12 \pm 0.06$ & Trace & $0.08 \pm 0.05$ & Trace \\
\hline $16: 0$ & $23.8 \pm 11.9$ & $2.5 \pm 0.4^{6}$ & $31.6 \pm 9.2$ & $23.9 \pm 2.0$ \\
\hline $16: l_{n-7}$ & $2.4 \pm 1.0^{6}$ & $0.60 \pm 0.25$ & $1.7 \pm 1.3$ & $3.3 \pm 1.5$ \\
\hline $17: 0$ & $0.52 \pm 0.29$ & $0.28 \pm 0.03$ & $0.70 \pm 0.32$ & $0.78 \pm 0.33$ \\
\hline $\left.\begin{array}{l}16: 2_{n-9} \\
16: 2_{n-6}\end{array}\right\}$ & $0.22 \pm 0.18$ & $0.06 \pm 0.05$ & $0.11 \pm 0.04$ & Trace \\
\hline $18: 0$ & $9.1 \pm 3.7$ & $34.8 \pm 1.4^{6}$ & $10.6 \pm 1.5$ & $10.9 \pm 1.2^{6}$ \\
\hline $18: l_{n-9}$ & $17.0 \pm 1.4$ & $4.9 \pm 1.5$ & $14.9 \pm 4.5$ & $0.78 \pm 0.53$ \\
\hline 19:0 & Trace & $0.24 \pm 0.23$ & Trace & $0.11 \pm 0.30$ \\
\hline $18: 2_{n-6}$ & $1.8 \pm 1.0^{7}$ & $2.2 \pm 2.2$ & $7.5 \pm 2.5^{7}$ & $0.12 \pm 0.09$ \\
\hline $20: 0$ & Trace & $0.17 \pm 0.03$ & $0.17 \pm 0.26$ & $3.1 \pm 1.9$ \\
\hline $\left.\begin{array}{l}18: 3_{n-3} \\
20: 1_{n-9}\end{array}\right\}$ & $0.54 \pm 0.08^{7}$ & $0.30 \pm 0.06$ & $0.19 \pm 0.03^{7}$ & $0.06 \pm 0.03^{6}$ \\
\hline $20: 2_{n-9}$ & $0.22 \pm 0.08$ & $0.12 \pm 0.06$ & $0.12 \pm 0.05$ & $0.07 \pm 0.03$ \\
\hline $20: 2_{n-6}$ & $0.11 \pm 0.09$ & $0.11 \pm 0.06$ & $0.34 \pm 0.28$ & Trace \\
\hline $20: 3_{n-9}$ & $1.1 \pm 0.7^{6}$ & $0.71 \pm 0.27^{7}$ & $0.56 \pm 0.20^{6}$ & Trace \\
\hline $\left.\begin{array}{l}20: 3_{n-6} \\
22: 0\end{array}\right\}$ & $1.6 \pm 0.7$ & $3.0 \pm 0.5^{6}$ & $4.7 \pm 2.2^{6}$ & $6.5 \pm 0.4^{8}$ \\
\hline $20: 4_{n-6}$ & $19.5 \pm 8.0$ & $24.7 \pm 3.3$ & $12.8 \pm 4.9^{6}$ & $0.60 \pm 0.24^{6}$ \\
\hline $22: 1_{n-9}$ & $0.18 \pm 0.26$ & & $0.07 \pm 0.03$ & $0.29 \pm 0.18$ \\
\hline $\left.\begin{array}{l}20: 4_{n-3} \\
23: 0\end{array}\right\}$ & $1.5 \pm 1.0$ & $2.2 \pm 1.3$ & $0.97 \pm 0.46$ & $2.6 \pm 1.1^{6}$ \\
\hline $22: 2_{n-9}$ & $0.17 \pm 0.18$ & $0.29 \pm 0.18$ & $0.52 \pm 0.60$ & $0.45 \pm 0.42$ \\
\hline $\left.\begin{array}{l}20: 5_{n-3} \\
22: 2_{n-6}\end{array}\right\}$ & $0.31 \pm 0.20^{7}$ & Trace & $0.36 \pm 0.19$ & \\
\hline $22: 3 n-9$ & $1.1 \pm 0.4^{7}$ & $0.34 \pm 0.25$ & Trace & $0.19 \pm 0.03$ \\
\hline $24: 0$ & $0.13 \pm 0.15$ & Trace & $2.4 \pm 3.5$ & $20.8 \pm 1.6$ \\
\hline $22: 4_{n-9}$ & $0.50 \pm 0.46$ & $0.23 \pm 0.13$ & & \\
\hline $\left.\begin{array}{l}22: 4_{n-6} \\
24: 1_{n-9}\end{array}\right\}$ & $6.9 \pm 1.6$ & $4.3 \pm 1.0^{6}$ & $2.6 \pm 3.7$ & $21.6 \pm 3.5^{9}$ \\
\hline $22: 5_{n-6}$ & $1.4 \pm 0.3^{7}$ & $2.3 \pm 1.7$ & $0.35 \pm 0.46$ & $0.61 \pm 0.38$ \\
\hline $22: 5_{n-3}$ & $0.65 \pm 0.63^{7}$ & $1.8 \pm 1.0^{6}$ & $0.85 \pm 1.11$ & $0.08 \pm 0.16$ \\
\hline $\left.\begin{array}{l}22: 6_{n-3} \\
26: 0\end{array}\right\}$ & $8.5 \pm 4.9$ & $13.6 \pm 1.9$ & $5.1 \pm 2.6$ & $1.3 \pm 0.2^{6}$ \\
\hline $\begin{array}{l}24.4_{n-6} \\
26: 1_{n-9}\end{array}$ & $0.18 \pm 0.20$ & $0.07 \pm 0.05$ & $\begin{array}{l}0.25 \pm 0.24 \\
0.19 \pm 0.25\end{array}$ & $1.5 \pm 0.3$ \\
\hline
\end{tabular}

Values, in percentage of peak areas, are given as means \pm SD. Statistical comparison is between neonates and adults (Table II) by $t$ test.

2 PE: phosphatidyl ethanolamine.

${ }^{3}$ PS : phosphatidyl serine.

${ }^{4} \mathrm{PC}$ : phosphatidyl choline.

${ }^{5} \mathrm{SP}$ : sphingomyelin.

${ }^{6} P<0.05$.

$7 P<0.01$.

8 Appears to be largely 22:0.

9 Appears to be largely $24: 1_{n-9}$.

Although the proportion of unsaturated fatty acids was smaller in erythrocytes from neonates than in those from adults, the proportion of polyunsaturated fatty acids was greater. Within the linoleic acid family, the content of 18:2 was considerably smaller, whereas the contents of $20: 4$, of its precursor $20: 3$, and of $22: 5$ were larger. Within the oleic acid family, the contents of
$20: 3$ (which was present in only trace amounts in erythrocytes of adults) and of 22:3 were significantly larger; the content of 20:1 was smaller. Within the linolenic acid family there was also a trend toward an increase in the amount of fatty acid with the largest number of double bonds (22:6).

In newborn infants the patterns of free fatty acids 
and of the fatty acids in neutral lipids and PL in the plasma were similarly altered as those found in PL of the erythrocyte membrane. The content of $18: 2_{\mathrm{n}-6}$ in free fatty acids, triglycerides, cholesterol esters, and PC was smaller whereas that of $20: 4_{n-6}$ was larger than in adults [33-35, 38, 50, 51].

The cause of the different fatty acid pattern in erythrocytes of newborn infants was not discussed by Crowley et al. [6] or by Neerhout [30]. It is, however, remarkable that there is a similarity in the changes in fatty acid composition caused by an essential fatty acid deficiency and by abetalipoproteinemia where a malabsorption of essential fatty acids is assumed [31, 45]. By dietary experiments it was proven that the smaller content of $18: 2_{n-6}$, the greater formation of $20: 3_{n-9}$ and the greater proportion of polyunsaturated fatty acids are characteristic of a deficiency of essential fatty acids [13, $17,22,32,41-43]$.

The lack of $18: 2_{n-6}$ in the fetus is not due to a maternal deficiency of this fatty acid $[34,50,51]$. However, there could be insufficient placental uptake of essential fatty acids by the fetus. The decreased amount of $18: 2_{\mathrm{n}-6}$ leads to changes in the regulation of the desaturation mechanism $[3,21]$, which result in a relative increase in the unsaturated fatty acids with the most double bonds within the different fatty acid families (e.g., $20: 3_{\mathrm{n}-9}, 22: 5_{\mathrm{n}-6}$ and $22: 6_{\mathrm{n}-3}$ ). So far it is unknown whether the altered fatty acid composition can replace the normal pattern in the erythrocyte membrane without any functional disturbances, and whether the known functional differences in erythrocytes of newborn infants can be explained by the altered PL and fatty acid composition.

\section{Summary}

Fatty acid compositions were analyzed by GLC, that of total PL after TLC separation from neutral lipids and glycosphingolipids, that of individual PL after TLC fractionation. The patterns of fatty acids in erythrocytes from adults, healthy newborn infants, and neonates with $\mathrm{Rh}$ erythroblastosis were compared.

\section{References and Notes}

1. Ackman, R. G.: An analysis of separation factors applicable in the gas-liquid chromatography of unsaturated fatty acid methyl esters on a polyester substrate. J. Amer. Oil Chem. Soc., 40: 564 (1963).

2. Bartlett, G. R.: Phosphorus assay in column chromatography. J. Biol. Chem., 234: 466 (1959).

3. Brenner, R. R., AND Peluffo, R. O.: Regulation of unsaturated fatty acids biosynthesis. I. Effect of unsaturated fatty acid of 18 carbons on the microsomal desaturation of linoleic acid into $\gamma$-linolenic acid. Biochim. Biophys. Acta, 176: 471 (1969).

4. Brockmann, U., and Gercken, G.: Quantitative eindimensionale Dünnschichtchromatographie der Erythrozytenphospholipide. Clin. Chim. Acta, 23: 489 (1969).

5. Cohen, P., And Derksen, A.: Comparison of phospholipid and fatty acid composition of human exythrocytes and platelets. Brit. J. Haematol., 17: 359 (1969).

6. Crowley, J., Ways, P., ANd Jones, J. W.: Human fetal erythrocyte and plasma lipids. J. Clin. Invest., 44: 989 (1965).

7. Cuzner, M. L., And Davison, A. N.: Quantitative thin layer chromatography of lipids. J. Chromatogr., 27: 388 (1967).

8. Dittmer, J. C., ANd Lester, R. L.: A simple, specific spray for the detection of phospholipids on thin-layer chromatograms. J. Lipid Res., 5: 126 (1964).

9. Dodge, J. T., And Phillips, G. B.: Composition of phospholipids and phospholipid fatty acids and aldehydes in human red cells. J. Lipid Res., 8: 667 (1967).

10. ETTRE, L. S., AND KABOT, F. J.: Relative response of fatty acid methyl esters on the flame ionization detector. J. Chromatogr., 11: 114 (1963).

11. Farquhar, J. W.: Human erythrocyte phosphoglycerides. I. Quantification of plasmalogens, fatty acids, and fatty aldehydes. Biochim. Biophys. Acta, 60: 80 (1962).

12. Farquhar, J. W., and Ahrens, E. H., JR.: Effects of dietary fats on human erythrocyte fatty acid patterns. J. Clin. Invest., 42: 675 (1963).

13. Fitch, C. D., Dinning, J. S., Witting, L. A., And Horwitt, M. K.: Influence of dietary fat on the fatty acid composition of monkey erythrocytes. J. Nutr., 75: 409 (1961).

14. Gercken, G., and BrockmanN, U.: Zusammensetzung der Phospholipide und deren Fettsäuremuster in Kaninchenerythrozyten und ghosts. Eur. J. Biochem., 8: 489 (1969).

15. Gier, J. de, Mandersloot, J. G., and van Deenen, L. L. M.: Lipid composition and permeability of liposomes. Biochim. Biophys. Acta, 150: 666 (1968).

16. Golde, L. M. G. van, Tomast, V., and van Deenen, L. L. M.: Determination of molecular species of lecithin from erythrocytes and plasma. Chem. Phys. Lipids, 1: 282 (1967).

17. Greenberg, L. D., AND Moon, H. D.: Alterations of blood fatty acids in single and combined deficiencies of essential fatty acids and vitamin $B_{6}$ in monkeys. Arch. Biochem. Biophys., 94: 405 (1961).

18. HAKEN, J. K.: Retention time relationships in the gas chromatography of the methyl esters of fatty acids. J. Chromatogr., 23: 375 (1966).

19. Haken, J. K.: Limitations of systematic relationships of gas chromatographic retention behaviour and structure of fatty acids. J. Chromatogr., 39: 245 (1969).

20. Hill, J. G., Kuksis, A., AND Beveringe, J. M. R.: The effect of diet on the phospholipid composition of the red blood cells of man. J. Amer. Oil Chem. Soc., 42: 137 (1965).

21. Holman, R. T., and Mohrhauer, H.: A hypothesis involving competitive inhibitions in the metabolism of polyunsaturated fatty acids. Acta Chem. Scand., 17: 84 (1963).

22. Holman, R. T., Caster, W. O., and Wiese, H. F.: The essential fatty acid requirement of infants and the assessment of their dietary intake of linoleate by serum fatty acid analy. sis. Amer. J. Clin. Nutr., 14: 70 (1964).

23. Hürter, P., Schröter, W., Schedel, I., ANd Gercken, G.: 
Phospholipids of red cells and blood plasma in adults, newborn infants and patients with $\mathrm{Rh}$ erythroblastosis. Pediatrics, 46: 259 (1970).

24. Jamieson, G. R., And Reid, E. H.: The analysis of oils and fats by gas chromatography. III. Separation factors of acetates, alcohols and hydrocarbons. J. Chromatogx., 26: 8 (1967).

25. Kates, M., Allison, A. C., And James, A. T.: Phosphatides of human blood cells and their role in spherocytosis. Biochim. Biophys. Acta, 48: 571 (1961).

26. Metcalfe, L. D., Schmutz, A. A., and Pelka, J. R.: Rapid preparation of fatty acid esters from lipids for gas chromatographic analysis. Anal. Chem., 38: 514 (1966).

27. Mrwa, T. K., MrkolajczaK, K. L., Earle, F. R., and Wolff, I. A.: Gas chromatographic characterization of fatty acids. Identification constants for mono- and dicarboxylic methyl esters. Anal. Chem., 32: 1739 (1960).

28. Moone, T. J.: Glycerol permeability of human fetal and adult exythrocytes and of a model membrane. J. Lipid Res., 9: 642 (1968).

29. Morrison, W. R., AND SMITH, L. M.: Preparation of fatty acid methyl esters and dimethylacetals from lipids with boron fluoride-methanol. J. Lipid Res., 5: 600 (1964).

30. Neerhout, R. C.: Erythrocyte lipids in the neonate. Pediat. Res., 2: 172 (1968).

31. Phillips, G. B., And Dodge, J. T.: Phospholipid and phospholipid fatty acid and aldehyde composition of red cells of patients with abetalipoproteinemia (acanthocytosis). J. Lab. Clin. Med., 71: 629 (1968).

32. Pormman, O. W., Andrus, S. B., Pollard, D., and Bruno, D.: Effects of long-term feeding of fat-free diets to cebus monkeys. J. Nutr., 74: 429 (1961).

33. RENKONEN, O.: Serum lipids of labouring mothers and newborn babies. Ann. Med. Exp. Biol. Fenn., 44, Suppl. 10: 1 (1966).

34. Robertson, A. F., ANd Sprecher, H.: A review of human placental lipid metabolism and transport. Acta Paediat. Scand. Suppl., 183: 1 (1968).

35. Robertson, A., Sprecher, H., And Wilcox, J.: Free fatty acid patterns of human maternal plasma, perfused placenta, and umbilical cord plasma. Nature, 217: 378 (1968).

36. Skipski, V. P., Peterson, R. F., Sanders, J., and Barclay, M.: Thin-layer chromatography of phospholipids using silica gel without calcium sulfate binder. J. Lipid Res., 4: 227 (1963).

37. Skipski, V. P., Smolowe, A. F., and Barclay, M.: Separation of neutral glycosphingolipids and sulfatides by thin-layer chromatography. J. Lipid Res., 8: 295 (1967).

38. Sprecher, H., AND Robertson, A.: Analysis of lecithin and cephalin fatty acids from human maternal and fetal blood, perfused placenta, chorion laeve, and amnion. J. Lab. Clin. Med., 70: 489 (1967).

39. Svennerholm, E., Ställberg-Stenhagen, S., and Svennerholm, L.: Fatty acid composition of sphingomyelins in blood, spleen, placenta, liver, lung and kidney. Biochim. Biophys. Acta, 125: 60 (1966).

40. Wagner, H., Hörhammer, L., and WolfF, P.: Dünnschicht- chromatographie von Phosphatiden und Glykolipiden. Biochem. Z., 334: 175 (1961).

41. WALker, B. L.: Chromatographic evidence for the occurrence of oleic acid metabolites in erythrocytes from essential fatty acid-deficient rats. Arch. Biochem. Biophys., 114: 465 (1966).

42. Walker, B. L., ANd Kummerow, F. A.: Dietary fat and the structure and properties of rat exythrocytes. III. Response of erythrocyte fatty acids to various dietary fats. J. Nutr., 82: 329 (1964).

43. Walker, B. L., and YURkowski, H.: Effect of cell age on erythrocyte fatty acid composition in rats on different dietary regimes. Biochem. J., 103: 218 (1967).

44. Ways, P., AND Hanahan, D. J.: Characterization and quantification of red cell lipids in normal man. J. Lipid Res., 5: 318 (1964).

45. Ways, P., Reed, C. F., and Hanahan, D. J.: Red-cell and plasma lipids in acanthocytosis. J. Clin. Invest., 42: 1248 (1963).

46. WiJnGaARDEN, D., VAN: Modified rapid preparation of fatty acid esters from lipids for gas chromatographic analysis. Anal. Chem., 39: 848 (1967).

47. Williams, J. H., Kuchmak, M., AND Witter, R. F.: Fatty acids in phospholipids isolated from human red cells. Lipids, 1: 391 (1966).

48. WoOdFord, F. P., AND VAN Gent, C. M.: Gas-liquid chromatography of fatty acid methyl esters: the "carbon-number" as a parameter for comparison of columns. J. Lipid Res., $I$ : 188 (1960).

49. Yamakawa, T.: Glycolipids of mammalian red blood cells. Colloq. Ges. Physiol. Chem., 16: 87 (1966).

50. ZeE, P.: Lipid metabolism in the newborn. I. Phospholipids in cord and maternal sera. Pediatrics, 39: 82 (1967).

51. ZEE, P.: Lipid metabolism in the newborn. II. Neutral lipids. Pediatrics, 41 : 640 (1968)

52. Vetren, Promonta, Hamburg, Germany.

53. All chemicals were reagent grade and purchased from Merck, Darmstadt, Germany, unless specified otherwise.

54. Janke and Kunkel, Staufen, Germany.

55. Schuchardt, München, Germany.

56. G 3, Schott, Mainz, Germany.

57. Model 402, Hewlett-Packard Company, Palo Alto, Calif.

58. Applied Science Laboratories, Inc., State College, Penna.

59. Lipid standards nos. 189-1, 189-3, 189-5, 189-7, 189-8, and nos. C 8004, D 9505, and E 0875 from Sigma Chemical Company, St. Louis, Mo.; nos. H 104, K 107, and K 108 from Applied Science Laboratories, Inc., State College, Penna.

60. Hewlett-Packard Company, Böblingen, Germany.

61. Supported in part by the Deutsche Forschungsgemeinschaft Grant no. Schr. 86/7.

62. A short communication was presented to the XIII International Congress of Hematology, München, Germany, 1970.

63. Requests for reprints should be addressed to: DR. G. GerCKEN, Department of Organic Chemistry and Biochemistry, University of Hamburg, 2 Hamburg 13, Papendamm 6, Germany.

64. Accepted for publication November 15, 1971. 